\title{
UTteR control through miRs: fine-tuning ATXN1 levels to prevent ataxia
}

\author{
Mingyi Xie ${ }^{1}$ and Maurice S. Swanson ${ }^{2}$ \\ ${ }^{1}$ Department of Biochemistry and Molecular Biology, UF Health Cancer Center, University of Florida, Gainesville, Florida 32610, \\ USA; $^{2}$ Department of Molecular Genetics and Microbiology, Center for NeuroGenetics, the Genetics Institute, University of \\ Florida, Gainesville, Florida 32610, USA
}

Pathomechanistic studies of neurodegenerative diseases have documented the toxic effects of mutant protein expression, misfolding, and aggregation. However, alterations in the expression of the corresponding wild-type (WT) gene, due to either variations in copy number or transcriptional regulation, have also been linked to Alzheimer's and Parkinson's diseases. Another striking example of this mutant and WT duality is spinocerebellar ataxia type 1 (SCA1) caused by an ATXN1 polyglutamine protein, although subtle variations in WT AXTN1 levels also lead to ataxia. In this issue of Genes \& Development, Nitschke and colleagues (pp. 1147-1160) delve into posttranscriptional events that fine-tune ATXN1 expression and uncover a key role for $5^{\prime}$ untranslated region (5' UTR)-miR760 interactions. Thus, this study not only provides significant insights into the complexities of modulating the expression of a dosage-sensitive gene but also highlights the critical importance of identifying noncoding polymorphisms as disease risk factors.

SCA1, a dominantly inherited and progressive ataxia characterized by severe loss of cerebellar Purkinje cells, is caused by the expansion of a CAG short tandem repeat in the ATXN1-coding region (Paulson et al. 2017). This expansion results in the expression of a mutant ATXN1 protein containing a polyglutamine (polyQ) tract that triggers enhanced stability and aberrant interactions with its transcriptional repressor partner, Capicua/CIC (Rousseaux et al. 2018). In support of this gain-of-function disease model, antisense oligonucleotide (ASO)-mediated ATXN1 depletion reduces motor deficits and increases survival of the Atxn $1^{154 \mathrm{Q} / 2 \mathrm{Q}}$ SCA1 mouse model (Friedrich et al. 2018). Perhaps more surprisingly, the RNAbinding protein PUMILIO1/PUM1, with dual functions in translational repression and mRNA turnover activation, binds to the ATXN1 3' UTR to regulate ATXN1 protein levels, and even a modest $30 \%-50 \%$ increase in WT ATXN1 in Pum1 ${ }^{+/-}$heterozygotes results in Purkinje

[Keywords: 5' UTR; neurodegeneration; SCA1; miRNA]

Corresponding author: mswanson@ufl.edu

Article is online at http://www.genesdev.org/cgi/doi/10.1101/gad.343020. 120 . cell and motor deficits that are rescued by ATXN1 reduction in Pum1 $^{+/-}$; Atxn1 ${ }^{+/-}$mice (Gennarino et al. 2015; Goldstrohm et al. 2018). These and additional observations suggest that ATXN1 provides an excellent regulatory system to study posttranscriptional mechanisms that control the expression levels of dosage-sensitive genes (Fig. 1A).

In this report, Nitschke et al. (2020) extend earlier observations from the Zoghbi laboratory (Lee et al. 2008; Gennarino et al. 2015) that several microRNAs (miRNAs), including miR19, miR101, and miR130, together with PUM1, coregulate ATXN1 levels (Fig. 1B). Mammalian miRNA-guided repression generally involves binding of the Argonaute (AGO)-miRNA complex (RNA-induced silencing complex [RISC]) to miRNA target sites together with recruitment of TNRC6 proteins and deadenylase complexes (CCR4-NOT and PAN2-PAN3) to modulate mRNA translation and turnover with miRNA target sites located predominantly in the 3' UTR (Bartel 2018). However, the investigators were intrigued by the lengthy ATXN1 5' UTR (971 bp) and the recent report of alternative splicing of exons 2 and 3 in the $5^{\prime}$ UTR as well as the presence of multiple upstream open reading frames (uORFs) (Manek et al. 2020).

As an initial test for a 5' UTR role in ATXN1 expression, the investigators generated $5^{\prime}$ UTR luciferase reporters, which showed that the ATXN1 5' UTR serves a strong negative regulatory function with decreases of both luciferase activity ( 10-fold) and RNA level (approximately twofold) compared with control. Since miRNAs targeting 5' UTRs have been reported to either enhance protein translation without affecting mRNA levels or down-regulate both the target transcript and corresponding protein (Zhou and Rigoutsos 2014), this result prompted a survey of potential miR-binding sites on ATXN1 mRNA combined with miR targets coordinately highly expressed with ATXN1. This approach yielded miR760 as their lead among 10 top candidates since it is coexpressed

(C) 2020 Xie and Swanson This article is distributed exclusively by Cold Spring Harbor Laboratory Press for the first six months after the full-issue publication date (see http://genesdev.cshlp.org/site/misc/terms.xhtml). After six months, it is available under a Creative Commons License (Attribution-NonCommercial 4.0 International), as described at http://creativecommons.org/licenses/by-nc/4.0/. 

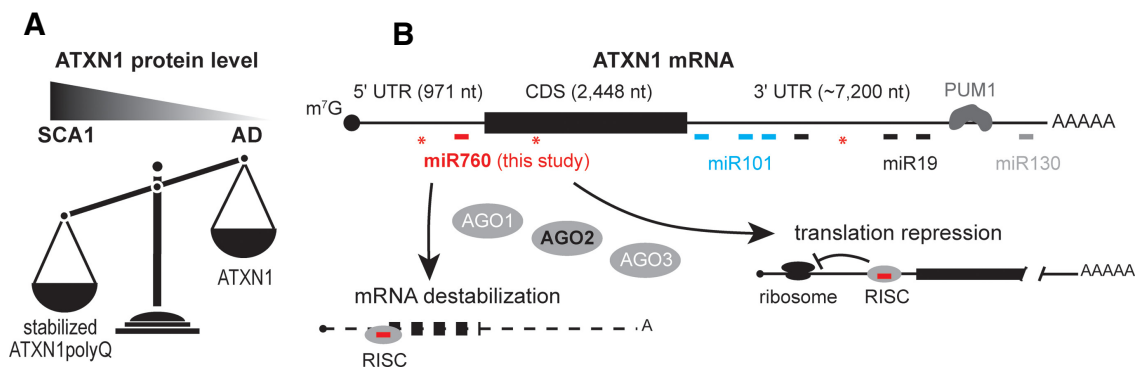

Figure 1. Neurodegenerative diseases impacted by ATXN1 gene expression. (A) For spinocerebellar ataxia type 1 (SCA1), a CAG repeat expansion in the ATXN1-coding region results in elevated levels of a stabilized ATXN1 polyglutamine (polyQ) protein, while in Alzheimer's disease (AD) declining ATXN1 levels in the hippocampus correlates with elevated $\beta$-secretase 1 (BACE1), suggesting that ATXN1 expression level is an $\mathrm{AD}$ risk factor. (B) ATXN1 mRNA is regulated by miRNAs targeting both the $5^{\prime}$ and $3^{\prime}$ untranslated regions (UTRs), together with the RNA-binding protein PUMILIO1 (PUM1). Nitschke et al. (2020) report a conserved miR760-binding site in the ATXN1 5' UTR, and miR760 associated with AGO1-3 down-regulates ATXN1 by decreasing mRNA stability and translation (RISC [RNA-induced silencing complex]). Target sites for miR760 (red), miR101 (cyan), miR19 (black), and miR130 (gray) are marked. Asterisks $\left(^{*}\right)$ denote sequences complementary to the miR760 seed but not functional.

with ATXN1 in 16 brain regions but, as predicted for a miRNA regulator, with a negative correlation between miR760 and ATXN1 levels in most of these regions, although not in the cerebellar cortex. Treatment of several cell types (DAOY and HEK293T) with miRNA mimics or inhibitors indicated that several top candidate miRs, including miR548a-3p, negatively regulated ATXN1 expression, although only the miR760 inhibitor led to increased ATXN1 levels. Among the four ATXN1 mRNA sites with miR760 seed region complementarity, only two of these are located in the $5^{\prime}$ UTR, and cell transfections of luciferase reporter constructs and several binding site deletion mutants identified miR760 site 2 as the functional site. Of the four mammalian AGO proteins (AGO1-4), AGO2 appears to play the predominant role, with AGO1 and AGO3 less active, and polysome analysis indicated that miR760-mediated negative regulation involves both decreased mRNA stability and translation. Interestingly, the active miR760 5' UTR-binding site is positioned just upstream (42 nt) of the ATXN1 translation initiation codon and downstream from the last predicted uORF, suggesting that RISC binding might block ribosome scanning (Fig. 1B). Of note, in the luciferase reporter assays, mutation of miR760 site 2 mildly offset ( 1.2-fold) the repressive function of the ATXN1 5' UTR ( 10-fold), inviting future research for additional gene regulatory mechanisms involving this unusually long $5^{\prime}$ UTR.

To clarify the contribution of miR760 regulation on ATXN1 levels in vivo, the investigators next characterized the effects of miR760 overexpression in Atxn1 $154 \mathrm{Q} /$ ${ }^{2 \mathrm{Q}}$ mice following stereotactic intracerebellar injections of AAV9 constructs expressing YFP-to monitor localization-and either a control or miR760. A 15-fold increase in miR760 expression led to a $25 \%$ decrease of both ATXN1 2Q and 154Q proteins in YFP-positive cerebellar regions together with significant improvements at $5 \mathrm{wk}$ after injection in motor coordination and learning by pole test and rotarod evaluations. While modulation of miR760 levels is problematic in humans given its association with cancer, an appealing extension provoked by this study is to expand searches for noncoding variants linked to ataxias that are not yet assigned to a particular gene mutation.
Overall, this impressive work provides enticing new insights into the multitiered posttranscriptional regulatory schemes required to fine-tune the levels of a dosage-sensitive gene implicated in multiple neurodegenerative diseases. Combined with cotranscriptional events, such as alternative RNA splicing and polyadenylation in the nucleus, the regulatory repertoire available to cells to rapidly modulate both RNA and protein levels is both currently impressive and likely to increase in the future.

\section{Acknowledgments}

This work was supported by National Institutes of Health grants to M.X. (R00CA190886 and R35GM128753) and M.S.S. (R01NS103172, R01NS098819, and P50NS048843).

\section{References}

Bartel DP. 2018. Metazoan microRNAs. Cell 173: 20-51. doi:10 $.1016 /$ j.cell.2018.03.006

Friedrich J, Kordasiewicz HB, O'Callaghan B, Handler HP, Wagener C, Duvick L, Swayze EE, Rainwater O, Hofstra B, Benneyworth $\mathrm{M}$, et al. 2018. Antisense oligonucleotide-mediated ataxin-1 reduction prolongs survival in SCA1 mice and reveals disease-associated transcriptome profiles. JCI Insight 3: e123193. doi:10.1172/jci.insight.123193

Gennarino VA, Singh RK, White JJ, De Maio A, Han K, Kim JY, Jafar-Nejad P, di Ronza A, Kang H, Sayegh LS, et al. 2015. Pumiliol haploinsufficiency leads to SCA1-like neurodegeneration by increasing wild-type Ataxin1 levels. Cell 160: 10871098. doi:10.1016/j.cell.2015.02.012

Goldstrohm AC, Hall TMT, McKenney KM. 2018. Post-transcriptional regulatory functions of mammalian pumilio proteins. Trends Genet 34: 972-990. doi:10.1016/j.tig.2018 .09 .006

Lee Y, Samaco RC, Gatchel JR, Thaller C, Orr HT, Zoghbi HY. 2008. miR-19, miR-101 and miR-130 co-regulate ATXN1 levels to potentially modulate SCA1 pathogenesis. Nat Neurosci 11: $1137-1139$. doi: $10.1038 / \mathrm{nn} .2183$

Manek R, Nelson T, Tseng E, Rodriguez-Lebron E. 2020. 5’UTRmediated regulation of Ataxin-1 expression. Neurobiol Dis 134: 104564. doi:10.1016/j.nbd.2019.104564

Nitschke L, Tewari A, Coffin SL, Xhako E, Pang K, Gennarino VA, Johnson JL, Blanco FA, Liu Z, Zoghbi HY. 2020. miR760 
UTteR control through miRs

regulates ATXN1 levels via interaction with its $5^{\prime}$ untranslated region. Genes Dev (this issue). doi:10.1101/gad.339317.120

Paulson HL, Shakkottai VG, Clark HB, Orr HT. 2017. Polyglutamine spinocerebellar ataxias - from genes to potential treatments. Nat Rev Neurosci 18: 613-626. doi:10.1038/nrn.2017.92

Rousseaux MWC, Tschumperlin T, Lu HC, Lackey EP, Bondar VV, Wan YW, Tan Q, Adamski CJ, Friedrich J, Twaroski K, et al. 2018. ATXN1-CIC complex is the primary driver of cerebellar pathology in spinocerebellar ataxia type 1 through a gain-of-function mechanism. Neuron 97: 1235-1243.e5. doi:10.1016/j.neuron.2018.02.013

Zhou H, Rigoutsos I. 2014. MiR-103a-3p targets the $5^{\prime}$ UTR of GPRC5A in pancreatic cells. RNA 20: 1431-1439. doi:10 $.1261 /$ rna.045757.114 


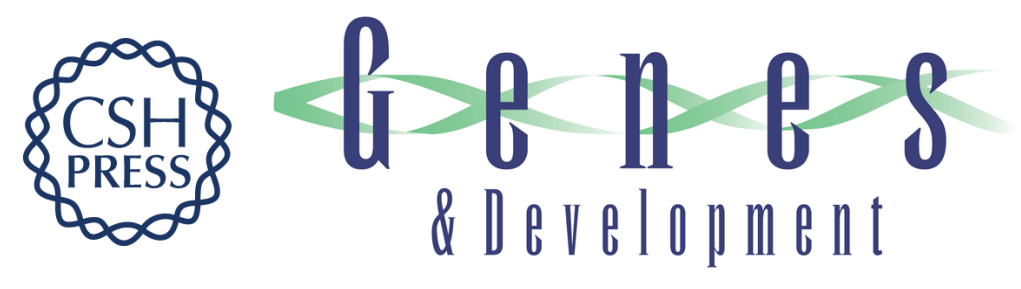

\title{
UTteR control through miRs: fine-tuning ATXN1 levels to prevent ataxia
}

\author{
Mingyi Xie and Maurice S. Swanson
}

Genes Dev. 2020, 34:

Access the most recent version at doi:10.1101/gad.343020.120
Related Content miR760 regulates ATXN1 levels via interaction with its $\mathbf{5 2}$ untranslated region Larissa Nitschke, Ambika Tewari, Stephanie L. Coffin, et al.
Genes Dev. September , 2020 34: 1147-1160

References This article cites 10 articles, 2 of which can be accessed free at: http://genesdev.cshlp.org/content/34/17-18/1107.full.html\#ref-list-1

Articles cited in: http://genesdev.cshlp.org/content/34/17-18/1107.full.html\#related-urls

Creative This article is distributed exclusively by Cold Spring Harbor Laboratory Press for the first Commons six months after the full-issue publication date (see License http://genesdev.cshlp.org/site/misc/terms.xhtml). After six months, it is available under a Creative Commons License (Attribution-NonCommercial 4.0 International), as described at http://creativecommons.org/licenses/by-nc/4.0/.

Email Alerting Receive free email alerts when new articles cite this article - sign up in the box at the top Service right corner of the article or click here.

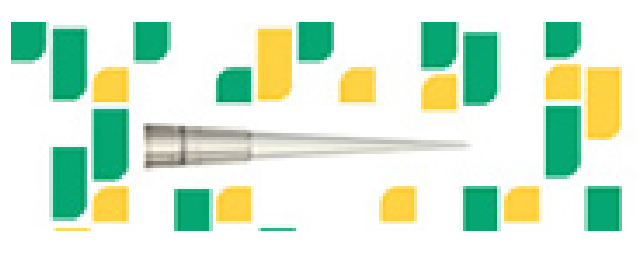

Focused on your science. 